Original article

\title{
A qualitative investigation into the rehabilitation experience of patients following wrist fracture
}

\author{
Rachael Bamford* and Dawn-Marie Walker ${ }^{\dagger}$ \\ *Occupational Therapy Department, King's Mill Hospital, Sutton-in-Ashfield, Nottinghamshire, UK; \\ †'School of Community Health Sciences, University of Nottingham, Nottingham, UK
}

Correspondence: Rachael Bamford, Occupational Therapy Department, Clinic 10, King's Mill Hospital, Mansfield Road, Sutton-in-Ashfield, Nottinghamshire NG17 4JL, UK. Email: rachael.bamford@sfh-tr.nhs.uk

\begin{abstract}
Introduction. Fractures of the wrist are often highly traumatic, leading to significant pain and reduction in an individual's home, work and leisure roles for a considerable time. Among the studies on wrist fracture, there is limited evidence which qualitatively explores the patient's rehabilitation experiences of this condition, and the impact they feel it has on their daily lives. The aim of this study was therefore to explore the experiences of working age people with dominant side wrist fracture in terms of the impact on their lives from the resulting loss of hand function, and the role that hand therapy plays in the rehabilitation process.

Method. Using a qualitative approach, semistructured interviews were carried out with six participants who were current or previous patients of an outpatient occupational therapy department and who had sustained wrist fracture. Three key themes equated to the impact the fracture had on their lives: 'functional ability', 'attitudes and expectations of self and others' and 'assessment and treatment in occupational therapy'. Results. The main findings showed that the impact of reduced ability evoked negative reactions and dependence on others. Lack of information on application and removal of plaster cast contributed towards early anxieties about the appearance and function of the hand. Patients' attitudes generally reflected taking some responsibility for their own progress. Occupational therapy input increased motivation, and particularly for those who attended rehabilitation sessions in the department, the therapy was valued.

Discussion. The recommendations from this study are that early and continued patient education is provided by the therapist, engaging relatives where appropriate, to alleviate patient and family anxieties and to help determine realistic expectations of recovery. While patients generally engage with objective measurements, making assessment and treatment relevant to their activities of daily living is essential to ensure they are motivated for therapy.
\end{abstract}

Keywords: Qualitative, wrist fracture, rehabilitation

\section{Introduction}

Wrist fracture is a common traumatic condition, representing the majority of upper limb fractures presenting to Emergency Departments and 30\% of cases referred to the Occupational Therapy (OT) outpatient department in the acute UK NHS Trust in which this study was conducted. Wrist fracture is a term used to describe a fracture to the distal radius with or without an associated ulna fracture. Most commonly, the distal radius is fractured in isolation ${ }^{1}$ and the majority are treated non-operatively. ${ }^{2}$ In addition to a home exercise regimen, individuals often engage in a rehabilitation programme in OT, comprising therapy, putty exercises, remedial activities, functional simulation exercise and work hardening. Patients are discharged once strength and range of movement enable them to resume daily occupations in their home, work and leisure roles, and complications such as pain, oedema and reduced sensation are resolved as much as possible.

The ability to participate in occupations has a direct link to health, and 'as part of their being' is used as a mechanism for individuals to 'exercise mind and body', in order to survive and fulfil their potential. ${ }^{3}$ The 'form' of occupation consists of aspects of carrying out a task that are directly observable and the 'meaning' relates to the significance of the occupation within the context of the 
individual's life, around which life roles are developed. ${ }^{4}$ As wrist fracture can impact on the occupational form, it can be very disruptive to the performance of occupations and roles that are meaningful in the life of the patient.

The importance of exploring the meaning and experience of hand injury and therapy has been highlighted. 5,6 Research into occupational circumstances, coping strategies, family support and what the hand injury means to the patient will increase knowledge of the functional impact of hand injury as an individual consequence. ${ }^{7,8}$ In order to identify qualitative evidence on rehabilitation from wrist fracture, literature searching of databases including Ovid Medline, AMED and Embase using search terms such as 'wrist fracture', 'distal radius fracture', 'hand therapy', 'physiotherapy' and 'occupational therapy' combined with 'qualitative', and 'rehabilitation' was undertaken. There is very little qualitative research into wrist fracture and subsequent therapy, and the literature on wrist fracture specifically is mainly quantitative in nature. The qualitative evidence reviewed here therefore centred around other types of hand injuries and general conditions.

Wrist fracture should not be considered a minor injury. ${ }^{1}$ Consequences for the patient can range from complete recovery to severe long-term limitations. Fractures in adults without osteoporosis tend to result from higher energy trauma, and damage to the ligaments surrounding the distal radio-ulna joint is common. This can impair treatment and recovery from wrist fracture in a usually working age group that often have high needs of wrist function for employment and leisure activities. ${ }^{9}$

From the quantitative evidence identified, it was found that therapy management of those with wrist fractures is diverse. ${ }^{10}$ A systematic review of 15 randomized controlled trials to investigate the effectiveness of a range of rehabilitation interventions provided by physiotherapists or occupational therapists found that no single treatment approach had the best effect in terms of objective measurements, functional assessments or patient self-report outcome measures, in follow-up periods ranging from four weeks to nine months. Research evidence was not strong because of the limited methodological quality of the studies reviewed, as well as the range of interventions offered and confounders such as motivation of trial participants. ${ }^{2}$

Additional quantitative research highlighted other patient oriented factors, such as perceived disability and adherence to home exercises as having an impact on rehabilitation outcomes. A correlational study by Wilcke et al. ${ }^{1}$ found that patient-perceived disability is only partially recognized by objective physical measurements, as it also depends on the patient's demands on their wrist. Therefore, despite X-ray findings and physical measurements used by therapists, the amount of limitation experienced also depends on the patient's unique situation and occupational requirements.

Lyngcoln et al. ${ }^{11}$ found that adherence to hand therapy home exercises is an important predictor of a good outcome, implying the importance of the patient's willingness to take some responsibility for their own progress. Cooper identified that the goal for therapists with wrist fracture patients is to facilitate restoration of preinjury function. $^{12}$

The present study is intended to explore in a qualitative manner whether participants felt objective measurements used by therapists reflected their own sense of ability, as well as attitudes towards the impact of their own role upon the recovery process.

A qualitative study by Chan and Spencer ${ }^{13}$ exploring adaptation to hand injury suggests that the relationship between physical recovery and psychosocial adaptation is complex, and evolves over time. Initial optimism can evolve into being disillusioned with progress that does not meet earlier expectations during the rehabilitation process. Individuals often undergo a process of re-evaluation of functional deficits in relation to the acceptance of limitations. ${ }^{14}$ Additionally, there can be individual differences in the role that significant others play in the recovery process, defined as 'independent versus interdependent' adaptive styles that have a strong influence on the coping strategies and recovery of the individual. $^{11}$

Other authors have highlighted the value of qualitative approaches in order to uncover individual meanings of experiences encountered. ${ }^{5,15}$

Themes that emerged from a study into the experience of flexor tendon injuries with five participants included trying to minimize the impact of the injury, struggling to cope and feeling dependent on others to help with daily activities. The injury therefore had a considerable impact on participants' lives. The author highlights a need for further research into understanding how disability and hand rehabilitation is experienced by patients with other conditions. $^{5}$

For health professionals qualitative research is an effective method of deepening understanding of conditions encountered on a regular basis, such as wrist fracture, in order to better serve patients. Such an approach is patient focused; however, as a therapist conducting this type of research, professional views inevitably impact upon the research process. Thorough reflection as to how this occurs is therefore required to ensure credibility within the research. ${ }^{16}$

\section{Study aim}

This study utilized qualitative methodology to explore the impact of dominant side wrist fracture upon participants. It explored daily activities and their experience of recovery throughout OT assessment and treatment, with a view to improving their therapy experience and outcomes.

Objectives:

- To investigate the experience of dominant side wrist fracture and its effects upon ability to carry out activities of daily living, particularly in productivity.

- To understand the patient's perspective on the outcomes used in OT and whether these have relevance to their situation.

- To explore patients' experiences of OT as part of their recovery from dominant side wrist fracture.

\section{Methods}

A qualitative approach was used to enable the experience of wrist fracture to be explored from the participant's point of view. Approval for the study was received from 
the local Research Ethics Committee. Adults of working age with fracture of the distal radius and/or ulna were identified by other therapists and invited to take part by letter. Further information was supplied in a participant information sheet. Written consent was obtained prior to data collection by semistructured interview. Participants were given pseudonyms to preserve their anonymity.

Participants were given a choice of interview venue: the participant's home or the therapy department. Two participants ('Judy' and 'Scott') chose to attend the therapy department. None of the participants had been patients of the researcher, but may have observed the researcher in their clinical role around the department. Prior to commencement of the interview, information was gathered on the participants' main work role, other medical history and self-reported hand dominance.

The inclusion criteria were as follows: diagnosis of closed distal radius fracture, with or without fracture of distal ulna; male or female, as the issues applying to them as working age people can be explored and compared; injury on the dominant side, as there will be similarities in the extent of functional limitations; of working age; fluent English speaking, as the participants need to provide informed consent and be able to engage in an interview with an English-speaking researcher; and sustained wrist fracture as sole injury, so that there are similarities in patient experience across the sample.

The exclusion criteria were as follows: patients receiving assessment and treatment with the researcher as their therapist, due to the high potential of bias on the results.

A semistructured interview guide was used to ensure that the aims of the study were addressed, while allowing flexibility for the participant to lead the discussion (see Box 1 for interview guide).

Interviews were audio-recorded and transcribed verbatim. A reflexive research diary ${ }^{17}$ was used after each interview to increase transparency of the research. This enabled the researcher to consider the reactions of the participants to questions asked, factors which may have influenced what was discussed and the possible influence of the researcher and the environment on the responses of the participants. Thematic analysis was carried out using a framework as described by Spencer et al. ${ }^{18}$ This added a structure to the data extraction and organization. To prevent the framework from dominating the participants' emerging accounts, this was used after the initial themes were identified and derived from the transcripts.

To understand the phenomenon of wrist fracture from the participants' perspectives, familiarity with the transcripts was gained by reading and re-reading, extracting significant statements and reflecting on the meanings of these while formulating themes to describe the experience of the individuals. The process was inductive; the concepts and themes arose from the responses of the participants, and consisted of three main phases (see Figure 1).

'Thematic charts' ${ }^{19}$ displayed raw data to illustrate the experience of the individuals in the study and variations between these in relation to the key themes that arose. The key concepts were chosen based on the amount of discussion and emphasis or reaction attached to them and the resonance with the study aims.
Box 1 Interview guide

How are you feeling today? (mood)

How have you found your treatment at the fracture clinic?

How have you found your treatment in occupational therapy?

How are you finding carrying out everyday activities (e.g.

work, home, leisure activities?)

What is your support from family, friends or work colleagues whilst you have this injury?

How is this injury affecting your life overall?

Have you ever been treated by an occupational therapist or hand therapist before?

What do you feel a hand therapist should be helping you with?

What are your thoughts on the assessments you have with the therapist? (prompt: assessment and measurement techniques used)

How are things going with your therapist?

Does your therapist address the issues that are important to you?

What are your thoughts on the current recovery of your wrist and hand?

What do you think it is that makes you more or less able than you have been?

What would you like to get out of your recovery?

Have you had any thoughts on how long this will take?

When do you think the therapist should end your treatment?

What is the overall impact of this injury on your life?

Do you expect this injury to have an impact on your life in the future?

Was there any particular reason you agreed to take part in this study?

Is there anything else you would like to tell me about your injury or treatment?

Following analysis, individuals were asked to complete a 'participant verification sheet' ${ }^{16}$ in which theme titles and transcript text were presented to ensure these represented what they expressed during the interview. Four participant verification sheets were returned and all agreed that the themes and supporting quotes represented their responses.

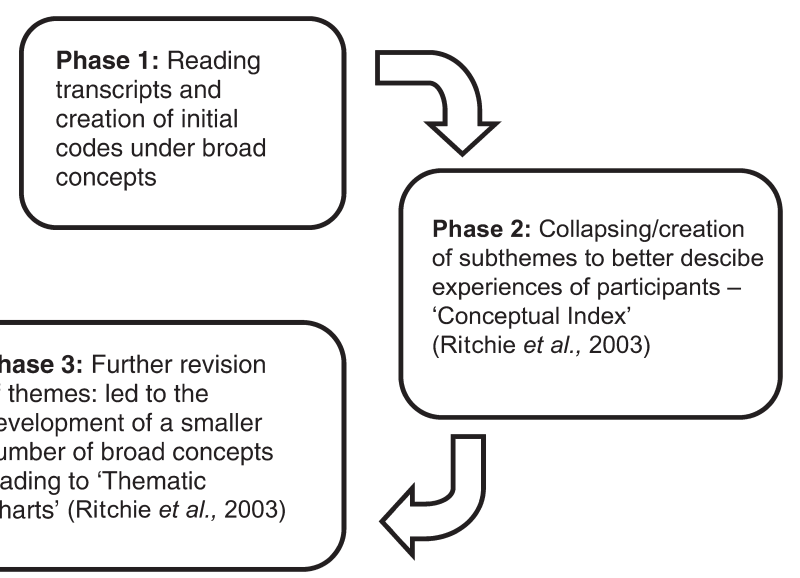

Figure 1 Process of data analysis 


\section{Results}

Two men and four women aged between 23 and 60 years (mean age 43), who were either current or previous patients of the service, participated in a semistructured interview. The aim was to have a group of 10 participants; however, time constraints meant that only six patients could be recruited. (Table 1)

Participants' experiences of wrist fracture can be represented under three broad themes as follows:

(1) Functional ability

(2) Attitudes and expectations of self and others

(3) Assessment and treatment in OT.

These themes emerged from the interviews and were the most common issues raised by the participants. Responses of three of the participants are summarized in relation to three sub-themes (Table 2).

\section{Functional ability}

Participants talked about their ability to perform day-to-day activities including work and leisure, and their struggles with being dependent on others.

\section{Depending on others}

Judy talked about being determined not to let her injury 'beat her' and how she strove to maintain her independence: 'I am not going to be handicapped by it. It is not going to beat me. I want to get on with my life'. All participants spoke about relying on others for aspects of everyday activities and stressed the importance of this support, especially in the early stages of treatment when in a plaster cast: 'My partner helped me a lot and when he was at work, friends came round at weekends and stuff to help me. If I got left at home, my partner had to iron my clothes before he went to work so I had something to wear' - Sarah.
Sarah described her feelings of being an 'invalid' in relation to depending on others, as found in a previous study. ${ }^{13}$ Participants linked this dependency with loss of confidence, frustration and anger; as Louise states: 'When you've not relied on anyone else and you've always been independent, to be dependent on other people I found frustrating'.

Despite negative reactions to the reduction in their abilities, participants acknowledged that others can play an important role in helping them regain independence, a finding made in previous research. ${ }^{5}$ Linda, talking about the support provided by her partner, explains: 'He came over, he was over in a couple of hours and it's a good job he did, otherwise I wouldn't have been able to manage'. Other participants spoke about the protectiveness of family members and the prompting they required to reduce this once their ability improved: 'My husband, for a long time afterwards, has driven me to work when there's been no need, I have said to him 'Why do you need to keep driving me to work, I'm okay I can do it myself' and he said 'I'm helping you' (Judy). This suggests that family members, partners and close friends, as well as those with the injury, need to adapt to living with injury and sometimes have difficulty withdrawing their support and allowing the individual to re-engage in meaningful occupations and roles. It is important that therapists acknowledge this, perhaps involve family members in assessment and treatment and also open discussion into levels of support required.

\section{Ability to work}

Participants took varying absences from work, depending on the job demands on their wrist and hand, and in Scott's case being a self-employed musician: 'It [plaster cast] came off just before Christmas sort of time so I had a lot of concerts, and again, I had to pull out of one of the concerts half way through because of the wrist swelling up'. This indicates that making an appropriately timed and successful return to work including consideration of financial pressures and adaptation of work tasks is an

Table 1 Summary of participants

\begin{tabular}{|c|c|c|}
\hline $\begin{array}{l}\text { Pseudonym, gender, age, occupation, } \\
\text { hand dominance }\end{array}$ & $\begin{array}{l}\text { Time since injury, workshop } \\
\text { treatment (WS) }\end{array}$ & $\begin{array}{l}\text { Details from information gathering tool, } \\
\text { e.g. relevant past medical history }\end{array}$ \\
\hline $\begin{array}{l}\text { 'Judy', Female, } 52 \\
\text { Administration Officer } \\
\text { Left }\end{array}$ & 9 months, no WS & $\begin{array}{l}\text { Previous wrist fracture a few years ago, } \\
\text { fractures in two left fingers } 2007\end{array}$ \\
\hline $\begin{array}{l}\text { 'Louise', Female, } 43 \\
\text { Discharge Facilitator and Waitress } \\
\text { Right }\end{array}$ & 3 months, WS & Possible fracture approx. 12 years ago \\
\hline $\begin{array}{l}\text { 'Scott', Male, } 23 \\
\text { Drummer/Drum Teacher } \\
\text { Right }\end{array}$ & 5 months, WS initially & Fractured collarbone aged 12 \\
\hline $\begin{array}{l}\text { 'Linda', Female, } 60 \\
\text { Library Assistant } \\
\text { Right }\end{array}$ & 2 months, no WS & $\begin{array}{l}\text { Mild depression awaiting osteoporosis } \\
\text { test. Humeral fracture as a child }\end{array}$ \\
\hline $\begin{array}{l}\text { 'Geoff', Male, } 54 \\
\text { Unemployed Joiner } \\
\text { Right }\end{array}$ & $2+1 / 2$ months, WS & 20 year history of depression \\
\hline $\begin{array}{l}\text { 'Sarah', Female, } 24 \\
\text { Call Centre Advisor } \\
\text { Right }\end{array}$ & 3 months, no WS & No other conditions \\
\hline
\end{tabular}


Table 2 Extract from thematic chart for Theme 1 - functional ability

\begin{tabular}{|c|c|c|c|}
\hline \multirow[b]{2}{*}{$\begin{array}{l}\text { Participant } \\
\text { name }\end{array}$} & \multicolumn{3}{|l|}{ Functional ability } \\
\hline & $\begin{array}{l}\text { 1a } \\
\text { Reduced ability and depending on } \\
\text { others }\end{array}$ & $\begin{array}{l}1 \mathrm{~b} \\
\text { Importance of work }\end{array}$ & $\begin{array}{l}\text { 1c } \\
\text { Hand dominance and adapting the } \\
\text { way ADL are carried out }\end{array}$ \\
\hline 'Judy' & $\begin{array}{l}\text { Initially help needed with dressing/getting } \\
\text { to work, by husband. Now only turning } \\
\text { hand for change difficult/aches. } \\
\text { Determined not to be 'handicapped' (2). }\end{array}$ & $\begin{array}{l}\text { Spent a while describing job (1). Work } \\
\text { useless with supporting return }(9+11) \\
\text { - emphasized strongly. Work useful } \\
\text { exercise - helped overall function (10). } \\
\text { Long awaited transfer to different } \\
\text { Department (11). }\end{array}$ & $\begin{array}{l}\text { Able to use both hands since young, } \\
\text { teacher tried to make her use her } \\
\text { right (4). Adapting things to be able } \\
\text { to do them at home e.g. jars (4). } \\
\text { Writes notes to Mum with right hand } \\
\text { (14). }\end{array}$ \\
\hline 'Louise' & $\begin{array}{l}\text { Finds waitressing difficult, picking plates } \\
\text { up, occasional use of splint (2). } \\
\text { Frustrating relying on other people (9). } \\
\text { Feels took things for granted before } \\
\text { injury (9). }\end{array}$ & $\begin{array}{l}\text { Colleagues at both jobs supportive. Not } \\
\text { able to make good use of time whilst } \\
\text { off work due to pain }(9,14) \text {. If couldn't } \\
\text { do waitressing job would have to leave } \\
\text { (14). }\end{array}$ & $\begin{array}{l}\text { Tried to bowl with left hand (4). Not } \\
\text { able to use right to do pots ( } 8) \text {, felt } \\
\text { 'funny'. Adapted to using left more } \\
\text { for carrying plates. }\end{array}$ \\
\hline 'Geoff' & $\begin{array}{l}\text { Light activity OK, heavy things still difficult } \\
\text { e.g. hoover, kettle, generally not bad (1). } \\
\text { Depression also had limiting impact (5). }\end{array}$ & $\begin{array}{l}\text { Does not yet feel ready to start home } \\
\text { improvements again (5). Has not } \\
\text { worked for a while due to depression } \\
\text { (7). }\end{array}$ & $\begin{array}{l}\text { Worried due to right handed (3). } \\
\text { Initially unable to write so tried left } \\
\text { hand, adapted grip of knife (5). Still } \\
\text { holds phone left hand when right } \\
\text { tired (13). }\end{array}$ \\
\hline
\end{tabular}

The bracketed numbers refer to the transcript page of the quote

important area to be discussed with patients, to enable them to engage once again in meaningful occupations.

Linda regarded returning to work as a milestone in her recovery, relating work to feeling like 'my own person again', which suggests that an aspect of self-identity is shaped by meaningful occupations and work, a finding also made in two studies. ${ }^{8,13}$

Linked with the previous sub-theme, some of the participants talked about the help of work colleagues once they returned to work: 'I've got to do it, but my colleagues at that job come and help me' - Louise (a waitress).

Consideration of job demands and return to work issues is therefore an important process for therapists to engage in with patients, as support to make this successful helps the individual to regain their sense of routine and normality.

\section{Hand dominance}

Hand dominance was an important issue for most of the participants. They tried to adapt to minimize loss of independence, by using their non-dominant hand for tasks. While wearing her plaster cast, Louise went tenpin bowling: 'I couldn't participate, so I did it with my left hand, I was all over the shop but we had a laugh about it'. The use of humour in this case helped to alleviate negative feelings of reduced dominant hand function.

Linda was worried that injuring her dominant wrist would mean that 'I'm never going to be able to do anything again; this is going to be terrible'. All participants expressed some early trepidation about regaining the use of the dominant hand, and this emphasizes the need for therapists to take an educational approach to reduce these anxieties.

Geoff acknowledges that the non-dominant hand can never be quite as good but that 'you adapt because you have to...' .

Judy, the only left-hand dominant participant, found it easier to adapt: 'Teachers and people like that would try and make you be right-handed. . So with being able to use both hands, I haven't found it really, you know, a negative thing'. This finding is supported by a comparative study, which found that left-handed individuals were significantly more dexterous with their non-dominant hand than were right-handed individuals. ${ }^{20}$

This suggests that adapting the performance of occupations in those with dominant side injuries is a common reaction in order to maintain independence. Judy's experience highlights that left-handed people may be more adaptable to using the non-dominant hand than right-handed people due to pressures to function in a society biased towards right handedness.

\section{Attitudes and expectations of self and others}

Participants discussed the attitudes of themselves and others towards their injury, and how expectations of recovery were shaped by this. 'If it carries on improving, I don't know if it will get much better than that, I've got the use of it' - Linda.

\section{Making progress and reaching potential}

Adapting to reduced ADL performance is an evolving process that participants encounter, linked with expectations of recovery. Most participants suggested that as long as they could continue their everyday activities, adaptation was not a problem: 'I want to lead my normal life, and if I need to make slight adjustments I am prepared to do that, but I want to do the best that I can' Judy.

All participants felt they were making some recovery and the general feeling was that, while they would like to reach full preinjury function, as long as they could perform everyday activities they would be content.

This suggests that patients go through a process of readjusting expectations of themselves and become 
willing to accept some limitations. They learned to adapt to limitations in movement and strength, and alter the occupational form. ${ }^{4}$ This process appears to be independent of the type of injury as it has also been evident in people who have sustained brain injury. ${ }^{14}$

Most individuals felt that they were beginning to resume their usual activities around two months after the injury, i.e. approximately a few weeks after the removal of the plaster cast. Scott highlighted that it is around this time that confidence increases, linked with regaining independence: 'I think most of it is the confidence of getting back into what you were doing before'. In contrast, fear of re-injury or self-perceived poor level of ability can lead to loss of confidence, a factor that can be influenced by therapist support and encouragement. Tailoring treatment towards the activities that are meaningful to the patient engenders a sense of increasing ability.

\section{Accepting the reality of the injury}

Accepting the reality of the injury has a strong link with making progress and early optimism can be replaced by feeling disillusioned. ${ }^{13}$ This is particularly the case if patient understanding about the nature of the injury is poor and they are unsure how to begin to use their hand and wrist again. Geoff felt he would progress more quickly than he did: 'In about three weeks to a month you think 'oh I'll be back to normal like' you know, it don't happen like that...'.

The importance of setting and regularly reviewing realistic goals in therapy can assist the adjustment process and therefore empower the patient with better knowledge of their condition and the process of recovery. This gives them a realistic idea of how much progress they are likely to make and as Linda states, improves their psychological coping in a situation they may not have experienced before: 'I suppose you've got nothing to compare it to. I think if I'd known that before, I wouldn't have been so down probably. I'd have known that it was going to get better, and I could do a bit more'. This highlights a need for education at the earliest opportunity, even before the patient presents in therapy, to prepare them regarding what to expect and what they can do to help themselves.

\section{Self-help and motivation}

Most participants recognized the need for them to take some responsibility during the rehabilitation process and identified treatment as a key element in their motivation: 'There is no point in coming to treatment if you are not going to take the advice. It is a waste of time...' - Judy.

However, Judy also talks about losing the motivation to do grip strengthening exercises with her stress ball once she could use her wrist and hand better: 'I don't feel too limited, I think really I should because I probably would be able to gain more benefit from it, but it is not actually holding me back, and perhaps that is the problem. If it was holding me back then I might be more. . .diligent [laughs] with using it'.

This indicates that the level of limitation in an individual's everyday occupations is a driving force behind motivation to adhere to home exercises. Therapists should be aware of this when advising a home exercise regimen. Discussing the patient's perspective, utilization of patient-rated outcome measures and making exercises meaningful and relevant to daily activities can improve motivation.

Louise talks of having low motivation to do exercises at home, preferring to exercise in the OT workshop: 'It's a bit boring, sat on your own doing the exercises, and you need somebody to motivate you... whereas at OT, you do it there, you work there, and it's a nice atmosphere to be working it in'.

This highlights some factors for consideration when prescribing home exercises, and the benefits to rehabilitation of an environment in which to carry out exercises. It also highlights other more social and motivational factors that contribute towards the patient's recovery.

\section{Assessment and treatment in OT}

Participants discussed their assessment and treatment in OT and the effect this has on their recovery.

\section{Assessment in OT}

Most participants felt that the objective measurements used by therapists gave them something to aim for; using the numerical values as markers of their progress: 'It was nice to see the measurements coming up with the exercises that I was doing, that I was getting better and stronger...' - Scott.

However, there were mixed opinions from respondents as to whether these accurately reflected their ADL ability. While Scott found them very encouraging, Linda felt that she would rather use what she could do every day to monitor her progress and that the measurements had limited meaning for her. Geoff found the strength test did not necessarily reflect what he could do: 'I think it was registering about fifty-nine pounds or something like that. But I couldn't lift a kettle [laughs]'. Geoff's meaningful activity was renovating his home, and he used this as an outcome for when he should be discharged: 'When I've started doing my DIY stuff again and I can handle all my tools again, that would pretty much be it for me'.

This highlights the importance of relating objective measurements to real-life situations and providing education on other factors involved in carrying out everyday tasks. So, while grip strength and range of movement can give an indication of hand function, they do not account for overall ability of the individual, which includes many other factors. $^{1,21}$

\section{Treatment in OT}

For Linda, there was a sense of hope instilled once she began treatment in OT: 'I came out walking on air, feeling there was light at the end of the tunnel'.

As Scott did not attend for regular treatment, he states that the OT role in encouraging and guiding was the most important for him, and he emphasized this repeatedly in the interview: 'I think it was more the comfort of voicing my worries and getting the answers that I needed rather than the actual coming in and doing the exercises in here'.

All participants felt that whether they attended the workshop or not, OT made a positive contribution to their recovery. For Linda this was vital: 'I don't know what I would have done if they [Consultant] hadn't sent me 
because I think I would have still been, you know, not using it'. The importance of being seen by an OT early was emphasized; due to limited education at the fracture clinic stage, participants subsequently felt anxious as to whether their wrist was 'normal' after the removal of the plaster cast: 'From when the cast first came off I was sometimes panicking as to should I really only be able to move it that far or should it go further' - Scott.

Orthopaedic fracture clinics are often pressured environments; there is limited time to educate the patient on what to expect and the patient's potential for retaining information in this environment may be reduced. It is therefore important for therapists to discuss the thoughts and ideas that patients have about their recovery and educate them on initial assessment. However, not all patients with wrist fractures are referred to OT. This therefore highlights a need to review standard patient information that can be issued upon the application and removal of plaster casts, to alleviate anxiety at this difficult stage. Patient information videos cause more information to be retained by patients ${ }^{22}$ and due to the availability of DVDs are cost-effective to produce; this may be an engaging and more accessible alternative, due to the options of various language voice overs and subtitles or sign language, and can avoid reading difficulties.

The responses of the participants reinforces the need for consideration of their individual functional demands and abilities, as well as objective measurements, when treatment and discharge planning. The need for early education was highlighted as an important aid to coping with the impact of the injury.

\section{Discussion}

This study adds to the existing although limited body of qualitative evidence in hand therapy. The findings are relevant to service delivery and local future patient satisfaction could be audited against the issues highlighted in this study. There are three components that can be discussed regarding trustworthiness of qualitative research: transferability, dependability and neutrality. ${ }^{16}$

Transferability: As with any qualitative research, the ability to apply findings to the population at large or other groups is limited; however, the detailed description within this study should enable readers to judge the similarity between settings and make judgements about the transferability of the findings. Previous qualitative studies with different patient groups have made similar findings to those of this study, ${ }^{5,13,14}$ although a larger group of participants would have enabled greater depth and scope of results.

Dependability: Triangulation of various methods of gathering data enables consistency to be checked. This study utilized the transcripts, as well as a research diary from which to gather data. This facilitated consideration of factors that influenced participants' responses during the interview, but was limited as a data collection tool per se.

Neutrality: This refers to freedom from bias. Keeping a reflective diary makes clear the potential sources of bias rather than removing them. It is likely that participants' knowledge of the researcher as a therapist would have biased responses, and the 'stepping out' of therapist to researcher role was not entirely possible.

\section{Reflexivity}

As described earlier, an important aspect of this research approach is to use reflexivity to identify participant and environmental factors that influence the interviews. ${ }^{18}$ There must also be consideration of professional presuppositions and biases that might influence interpretation of the experiences talked about throughout the interviews. $^{23}$

\section{Research diary}

There were no negative or emotional reactions to questions asked. As a clinical researcher, probing may have been towards the types of questions asked during patient assessment and perhaps not as participant led as they might have been. Some participants asked questions related to their condition despite the researcher requesting before the interview commenced to be considered a researcher rather than a therapist. These were addressed if it was felt that to decline would interrupt the flow of the interview by preventing the participant from concentrating on the discussion rather than specific concerns. This is an example of duty of care issues to consider as a therapist carrying out research: when participants ask

treatment-related questions, the therapist as a researcher may feel obliged to answer. As this did occur during two of these interviews, this may have influenced the data collection and interpretation. In addition, the intention was to interview in participants' homes to reduce the potential bias in their answers from being interviewed in the therapy department, and to avoid perception of the researcher as a therapist. However, the responses of two participants who declined this were not dissimilar to those interviewed at home.

Exploring the meaning of wrist fracture from the participant's perspective and using this to inform and improve service delivery with this group of patients will inevitably mean that the clinician's perspective is applied in order to extract the important themes to achieve this aim. The researcher as an OT has higher sensitivity to issues highlighted by participants that relate to theory and practice of therapy and is bound to apply OT theory to statements made by participants, perhaps viewing them more as patients. This may have been alleviated by conducting the study in a different department, or the interviews being carried out by a research assistant, although in a study of this scale this would not be feasible.

A higher number of participants would have added more breadth to the responses and experiences of participants, but was not possible due to time constraints. Also as the interviews were conducted after the injury and therapy, responses are open to recall bias.

An alternative method of data collection, for example a questionnaire, may have been less open to researcher influence and would have enabled a larger sample. However, this method would not have given an in-depth description of participants' experiences as an interview does. The intention was not to generalize to the whole 
population of patients, but rather to provide an indication of the types of issues a wider group of people may face, through in-depth investigation of a smaller sample.

\section{Conclusion}

The impact of dominant side wrist fracture and the patient perspective on outcomes and treatment in OT have been explored, providing an insight into the patient experience of this injury. Themes developed from the data serve to illustrate the experience from the patient's point of view and factors to consider during assessment and treatment. This study contributes towards qualitative knowledge of the meaning of wrist fracture and considerations for improving the patient experience can be taken from this.

Acknowledgements: We thank the participants who volunteered their time to assist with data collection, and Sarah Woodbridge, OT and Clinical Supervisor for providing invaluable advice and guidance throughout.

Competing interests: None declared.

Accepted: 24 March 2010

\section{References}

1 Wilcke MKT, Abbaszadegan H, Adolphson PY. Patient-perceived outcome after displaced distal radius fractures: a comparison between radiological parameters, objective physical variables, and the DASH score. J Hand Ther 2007;20:290-9

2 Handoll HHG, Madhok R, Howe TE. A systematic review of rehabilitation for distal radius fractures in adults. Br J Hand Ther 2003;8:16-23

3 Wilcock A. Occupation for Health Volume 1: A Journey from Self Health to Prescription. London: British Association of Occupational Therapists, 2001

4 Clark F, Wood W, Larson E. Occupational science: occupational therapy's legacy for the 21st century. In: Neistadt ME, Crepeau EB eds. Willard and Spackman's Occupational Therapy, 9th edn. Philadelphia: Lippincott, 1998
5 Fitzpatrick N. A phenomenological investigation of the experience of patients during a rehabilitation programme following a flexor tendon injury to their hand. Br J Hand Ther 2007;12:76-82

6 Chan J, Spencer J. The usefulness of qualitative knowledge development in hand therapy. J Hand Ther 2004;17:1-5

7 Fitzpatrick N, Presnell S. Can occupational therapists be hand therapists? Br J Occup Ther 2004;67:508-10

8 Schier JS, Chan J. Changes in life role after hand injury. J Hand Ther 2007;20:57-69

9 Lindau T. Distal Radius Fractures and Effects of Associated Ligament Injuries. Lund, Sweden: Department of Orthopaedics, Lund University, 2000

10 MacDermid JC, Richards RS, Roth JH. Distal radius fracture: a prospective outcome study of 275 patients. I Hand Ther 2001; 14:154-64

11 Lyngcoln A, Taylor N, Pizzari T, Baskus K. The relationship between adherence to hand therapy and short-term outcome after distal radius fracture. J Hand Ther 2005;18:2-7

12 Cooper C. Fundamentals of Hand Therapy: Clinical Reasoning and Treatment Guidelines for Common Diagnoses of the Upper Extremity. Missouri: Mosby Elsevier, 2006

13 Chan J, Spencer J. Adaptation to hand injury: an evolving experience. Am J Occup Ther 2004;58:128-39

14 Conneeley AL. Quality of life and traumatic brain injury: a one-year longitudinal qualitative study. Br J Occup Ther 2003;66:440-6

15 Bear-Lehman J. A word about qualitative research. J Hand Ther 2002;15:85-86

16 Crepeau EB, Deitz JC. Qualitative research. In: Neistadt ME, Crepeau EB eds. Willard and Spackman's Occupational Therapy, 9th edn. Philadelphia: Lippincott, 1998

17 Finlay L, Gough B. Reflexivity: A Practical Guide for Researchers in Health and Social Sciences. Oxford: Blackwell, 2003

18 Spencer L, Ritchie J, O'Connor W. Analysis: practices, principles and processes. In: Ritchie J, Lewis J eds. Qualitative Research Practice: A Guide for Social Science Students and Researchers. London: Sage, 2003

19 Ritchie J, Spencer L, O'Connor W. Carrying out qualitative analysis. In: Ritchie J, Lewis J eds. Qualitative Research Practice: A Guide for Social Science Students and Researchers. London: Sage, 2003

20 Hodges L, Adams J. Grip strength and dexterity: a study of variance between right- and left-handed healthy individuals. Br J Hand Ther 2007;12:15-27

21 Tremayne A, Taylor N, McBurney H, Baskus K. Correlation of impairment and activity limitation after wrist fracture. Physiother Res Int 2002;7:90-9

22 Weston J, Hannah M, Downes J. Evaluating the benefits of a patient information video during the informed consent process. Patient Educ Counsel 1997;30:239-45

23 Ahern K. Ten tips for reflexive bracketing. Qual Health Res 1999;9:407-11 